\title{
ANALISIS WAKTU TUNGGU PELAYANAN RESEP PADA PASIEN RAWAT JALAN DI RSUD DR. H. ABDUL MOELOEK PROVINSI LAMPUNG
}

\section{Analysis Of Prescription Service Waiting For Reception Patients In DR. H. ABDUL MOELOEK LAMPUNG province}

\author{
Subur Widodo ${ }^{1}$, Masyuri Yusuf ${ }^{2}$, M. Desirwan Dinata ${ }^{3}$ \\ Fakultas MIPA, Jurusan Farmasi Universitas Tulang Bawang Lampung \\ Email : suburwidodo81@ gmail.com \\ HP. 0813-6948-1003
}

\begin{abstract}
Pharmaceutical services are health services in hospitals that are expected to meet minimum service standards (SPM) in an effort to improve the quality of services to patients. One of the pharmaceutical service categories in the minimum service standard (SPM) in hospitals is the waiting time for prescription services in the form of nonconcoction drugs is the grace period from the time the patient submits a prescription to receiving non-concoction drugs with a minimum standard set by the Ministry of Health that is $\leq 30$ minutes, whereas the waiting time for prescription concoction services is the grace period from the time the patient submits the prescription until receiving the concoction drug that is $\leq 60$ minutes. This research was conducted to analyze the waiting time for outpatient prescription services in Dr. H. Abdul Moeloek based on hospital minimum service standards (SPM) as an overview of prescription services, evaluation materials and pilots in an effort to improve the quality of pharmaceutical services. This research will be conducted at the pharmacy outpatients Dr. H. Abdul Moeloek in August - September 2019 with a sample of 172 recipes, consisting of 98 non-concoction recipes and 74 recipe concoctions. Based on the research that has been done, the results of waiting time for non-concoction prescription services in the Outpatient Installation of Dr. H. Abdul Moeloek is in accordance with the SPM at the Hospital with an average waiting time of 11 minutes. Waiting time for prescription concoction services in Dr. Outpatient Hospital Installation $\mathrm{H}$. Abdul Moeloek is in accordance with the SPM at the Hospital with an average waiting time of 19.4 minutes.
\end{abstract}

Keywords: Pharmaceutical services, waiting time, pharmaceutical service standards.

\begin{abstract}
Abstrak
Pelayanan kefarmasian merupakan pelayanan kesehatan di rumah sakit yang diharapkan dapat memenuhi standar pelayanan minimal (SPM) dalam rangka upaya peningkatan mutu pelayanan kepada pasien. Salah satu kategori pelayanan farmasi dalam standar pelayanan minimal (SPM) di rumah sakit adalah waktu tunggu pelayanan resep berupa obat non racikan merupakan tenggang waktu mulai pasien menyerahkan resep sampai dengan menerima obat non racikan dengan standar minimal yang ditetapkan kementerian kesehatan yaitu $\leq 30$ menit, sedangkan waktu tunggu pelayanan resep obat racikan adalah tenggang waktu mulai pasien menyerahkan resep sampai dengan menerima obat
\end{abstract}


racikan yaitu $\leq 60$ menit. Penelitian ini dilakukan untuk menganalisa waktu tunggu pelayanan resep pasien rawat jalan di RSUD Dr. H. Abdul Moeloek berdasarkan standar pelayanan minimal (SPM) rumah sakit sebagi gambaran pelayanan resep, bahan evaluasi dan percontohan dalam upaya peningkatan mutu pelayanan kefarmasian. Penelitian ini akan dilakukan di apotek pasien rawat jalan RSUD Dr. H. Abdul Moeloek bulan Agustus September 2019 dengan sampel sebanyak 172 resep, terdiri dari 98 resep non racikan dan 74 resep racikan. Berdasarkan penelitian yang telah dilakukan didapatkan hasil waktu tunggu pelayanan resep non racikan di Instalasi Rawat Jalan RSUD Dr. H. Abdul Moeloek sudah sesuai dengan SPM di Rumah Sakit dengan waktu tunggu rata - rata 11 menit. Waktu tunggu pelayanan resep racikan di Instalasi Rawat Jalan RSUD Dr. H. Abdul Moeloek sudah sesuai dengan SPM di Rumah Sakit dengan waktu tunggu rata rata 19,4 menit.Terdapat Perbedaan waktu tunggu resep non racikan dan racikan terdapat pada tahapan verifikasi dan penyiapan obat.

Kata kunci : Pelayanan kefarmasian, waktu tunggu, standar pelayanaan kefarmasian.

\section{PENDAHULUAN}

Manusia merupakan makhluk ciptaan tuhan yang diberi sakit dan sehat, dengan adanya riwayat sakit pada manusia, maka adanya pelayanan kesehatan untuk mengatasi sakit tersebut. Pelayanan kesehatan banyak jenisnya diantaranya yaitu pelayanan kesehatan tingkat pertama dan pelayanan kesehatan tingkat lanjutan yaitu rumah sakit (1). Rumah Sakit adalah institusi pelayanan kesehatan yang menyelenggarakan pelayanan kesehatan perorangan secara paripurna yang menyediakan pelayanan rawat inap, rawat jalan, dan gawat darurat. Penyelenggaran pelayanan kesehatan di rumah sakit mempunyai karakteristik dan organisasi yang sangat kompleks (2).

Rumah sakit merupakan sarana kesehatan yang memberikan pelayanan kesehatan kepada masyarakat. Pelayanan kesehatan yang diselenggarkan oleh rumah sakit salah satunya adalah pelayanan kefarmasian. Pelayanan kefarmasian yang dilaksanakan oleh rumah sakit meliputi pengelolaan sediaan farmasi, alat kesehatan dan bahan medis habis pakai, dan pelayanan farmasi klinis (3). Pelayanan kefarmasian merupakan pelayanan kesehatan di rumah sakit yang diharapkan dapat memenuhi standar pelayanan minimal (SPM) dalam rangka upaya peningkatan mutu pelayanan kepada pasien (4).

Rumah Sakit Umum Daerah Abdul Moeloek adalah sebuah rumah sakit tipe $A$ yang terletak di Bandar Lampung, Indonesia. Rumah sakit ini berada di JI. Dr. Rivai dan di bawah pengelolaan Pemerintah Provinsi Lampung. Rumah Sakit Umum Daerah Abdul Moeloek saat ini menjadi rumah sakit rujukan tertinggi untuk rumah sakit di 15 kabupaten/kota di Provinsi Lampung. Pasien rawat jalan di Instalasi Farmasi Rumah Sakit Umum Daerah Abdul Moeloek berjumlah rata-rata 189 pasien yang terdiri dari pasien obat non racikan dan obat racikan.

Berdasarkan uraian diatas maka peneliti tertarik melakukan penelitian tentang Analisis Waktu Tunggu Pelayanan Resep Pada Pasien Rawat Jalan di RSUD Dr. H. Abdul Moeloek Provinsi Lampung. Penelitian ini dilakukan untuk menganalisa waktu tunggu pelayanan resep pasien rawat jalan di RSUD Dr. H. Abdul Moeloek berdasarkan standar pelayanan minimal (SPM) rumah sakit sebagi gambaran pelayanan resep, bahan evaluasi dan percontohan dalam upaya peningkatan mutu pelayanan kefarmasian. 


\section{METODE PENELITIAN}

\section{Instrumen Penelitian}

Pada penelitian ini instrumen yang digunakan peneliti untuk pengumpulan data dengan melakukan wawancara secara langsung kepada informan, melakukan observasi pada kegiatan

pelayanan resep pasien dan telaah dokumen. Instrumen yang digunakan pada penelitian ini adalah pedoman

\begin{tabular}{|c|c|c|c|}
\hline No. & $\begin{array}{c}\text { Jenis } \\
\text { Resep }\end{array}$ & Jumlah & Persentase \\
\hline 1 & $\begin{array}{l}\text { Non } \\
\text { Racikan }\end{array}$ & 98 & $57 \%$ \\
\hline 2 & Racikan & $\frac{74}{172}$ & $\frac{43 \%}{100 \%}$ \\
\hline
\end{tabular}

wawancara, pedoman telaah dokumen, lembar observasi, alat tulis, dan alat perekam agar dapat memperkuat akurasi data.Sedangkan untuk pengumpulan data kuantitatif berupa formulir pencatatan waktu tunggu, stopwatch dan alat tulis.

\section{Pengumpulan Data}

Pengumpalan data dilakukan dengan cara observasi pada kegiatan farmasi rawat jalan RSUD Dr. $\mathrm{H}$. Abdul Moeloek.

3) Resep jaminan dan non jaminan yang dilayani di Apotek Instalasi Rawat Jalan RSUD Dr. $\mathrm{H}$. Abdul Moeloek Provinsi Lampung.

b) Kriteria Ekslusi

1) Resep karyawan RSUD Dr. H. Abdul Moeloek Provinsi Lampung.

2) Obat hasil resep yang tidak diambil langsung oleh pasien.

\section{HASIL DAN PEMBAHASAN}

\section{A. Karakteristik Resep Instalasi}

Rawat Jalan RSUD Dr. H. Abdul Moeloek Provinsi Lampung

Dari hasil penelitian, didapat jumlah sampel dalam penelitian ini sebanyak 172 resep, terdiri dari 98 resep non racikan dan 74 resep racikan. Persentase resep racikan dan non racikan :

Tabel 4.1 Karakteristik Resep

Hasil penelitian yang dilakukan di RSUD Dr. H. Abdul Moeloek diperoleh data dari 172 sampel resep terdapat 98 (57\%) resep

\begin{tabular}{|l|c|c|c|c|c|c|c|c|c|c|c|}
\hline & $\begin{array}{c}\text { Penerimaan } \\
\text { Resep }\end{array}$ & \multicolumn{2}{|c|}{$\begin{array}{c}\text { Verifikasi } \\
\text { Resep }\end{array}$} & \multicolumn{2}{c|}{$\begin{array}{c}\text { Penyiapan } \\
\text { Obat }\end{array}$} & \multicolumn{2}{c|}{$\begin{array}{c}\text { Pemberian } \\
\text { Etiket }\end{array}$} & \multicolumn{2}{c|}{$\begin{array}{c}\text { Penyerahan } \\
\text { Obat }\end{array}$} & \multirow{2}{*}{ Total } \\
\cline { 2 - 12 } & T & D & T & D & T & D & T & D & T & D & \\
\hline $\begin{array}{l}\text { Total } \\
\text { Keseluruhan }\end{array}$ & 57,6 & & 80,4 & 42,9 & 291,9 & 28,8 & 328,7 & 33,1 & 155,4 & 24,5 & 1083,4 \\
\hline Rata - Rata & 0,6 & & 0,8 & 0,4 & 3,0 & 0,3 & 3,4 & 0,3 & 1,6 & 0,3 & 11,0 \\
\hline
\end{tabular}

pelayanan resep pasien rawat jalan RSUD Abdul Moeloek Provinsi Lampung berdasarkan kriteria inklusi. Adapun kriteria yang digunakan sebagai berikut :

\section{a) Kriteria Inklusi}

1) Resep pasien rawat jalan di Apotek Instalasi Rawat Jalan RSUD Dr. H. Abdul Moeloek Provinsi Lampung.

2) Resep obat racikan dan non racikan yang dilayani instalasi non racikan dan $74(43 \%)$ resep racikan.

\section{B. Resep Non Racikan}

Dari hasil penelitian dapat dilihat waktu tunggu pelayanan resep non racik berdasarkan tahapan pelayanan resep sebagai berikut :

Tabel 4.2 Resep Non Racikan

Keterangan:

$\mathrm{T}=$ Tindakan

$\mathrm{D}=$ Delay 
Hasil penelitian yang dilakukan di RSUD Dr. H. Abdul Moeloek diperoleh data dari 98 sampel resep non racik rata rata waktu penerimaan resep tindakan 0,6 menit dan tidak ada delay, verifikasi resep tindakan 0,8 menit dan delay 0,4 menit, penyiapan obat tindakan 3 menit dan delay 0,3 menit, pemberian etiket tindakan 3,4 menit dan delay 0,3 menit, penyerahan obat tindakan 1,6 menit dan delay 0,3 menit.

\section{Penerimaan Resep}

Hasil penelitian waktu tunggu resep non racikan pada tahapan peneriman resep adalah sebagai berikut :

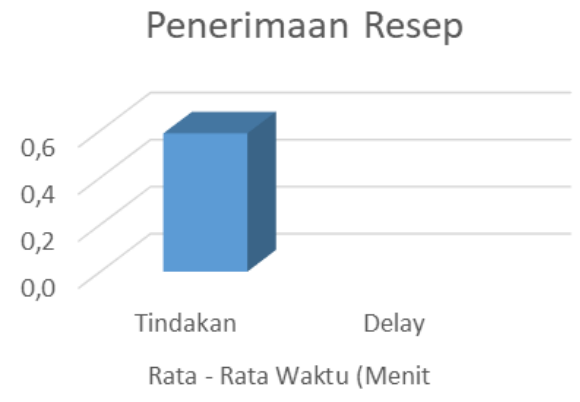

Gambar 4.1 Penerimaan Resep Non Racikan

Hasil penelitian yang dilakukan di RSUD Dr. H. Abdul Moeloek tahapan penerimaan resep non racikan membutuhkan rata - rata waktu tindakan 0,6 menit dan tidak terdapat delay. Pada proses penerimaan resep terdapat 4 loket pada apotek instalasi rawat jalan dan menggunakan alat bantu elektronik sehingga tidak ada delay. waktu pelayanan dan lama waktu tunggu. Faktor yang mempengaruhi penerimaan resep adalah proses registrasi artinya proses bagaimana sistem resep masuk ke dalam instalasi farmasi untuk dilakukan pelayanan peletakan loket yang banyak dan kurang tepat dapat berpotensi membingungkan pasien dalam hal mencari loket (12).

\section{Verifikasi Resep}

Hasil penelitian waktu tunggu resep non racikan pada tahapan verifikasi resep adalah sebagai berikut :

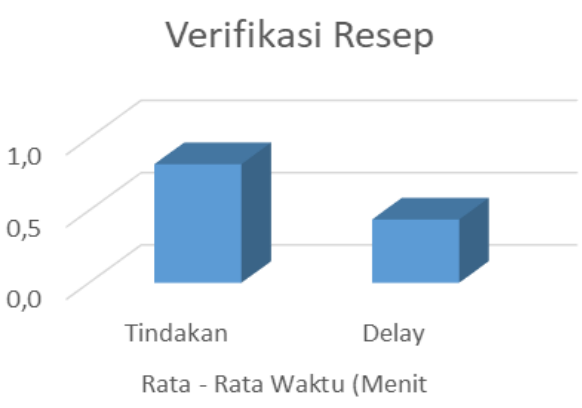

Gambar 4.2 Verifikasi Resep Non Racikan

Hasil penelitian yang dilakukan di RSUD Dr. H. Abdul Moeloek tahapan penerimaan resep non racikan membutuhkan rata - rata waktu tindakan 0,8 menit dan delay 0,4 menit. Pada proses verifikasi resep dilakukan nya skrining resep oleh apoteker yang melihat dan menelaah fase farmasetik dan fase klinis. Delay diakibatkan karena proses waktu skrining dan SDM yang terbatas membuat beberapa resep delay.

\section{Penyiapan Obat}

Hasil penelitian waktu tunggu resep non racikan pada tahapan verifikasi resep adalah sebagai berikut :

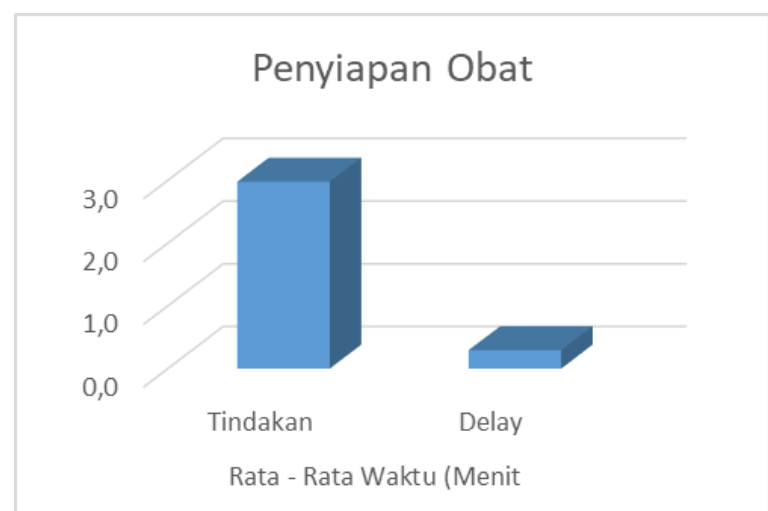

Gambar 4.3 Penyiapan Obat Non Racikan 
Hasil penelitian yang dilakukan di RSUD Dr. H. Abdul Moeloek tahapan penyiapan obat non racikan membutuhkan rata - rata waktu tindakan 3 menit dan delay 0,3 menit.

\section{Pemberian Etiket}

Hasil penelitian waktu tunggu resep non racikan pada tahapan pemberian etiket adalah sebagai berikut :

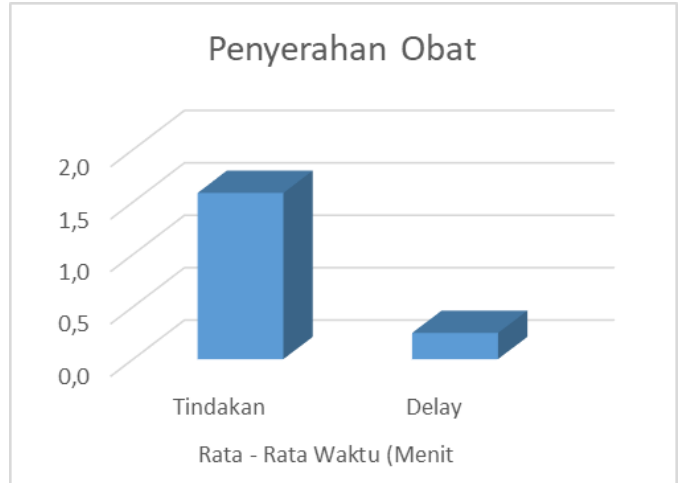

Gambar 4.5 Penyerahan Obat Non Racikan

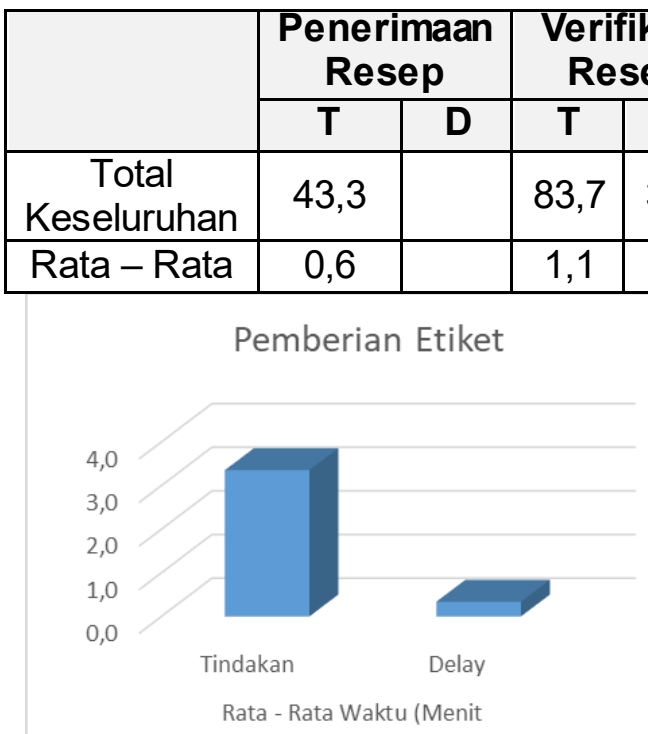

Gambar 4.4 Pemberian Etiket Non Racikan

Hasil penelitian yang dilakukan di RSUD Dr. H. Abdul Moeloek tahapan pemberian etiket non racikan membutuhkan rata - rata waktu tindakan 3,4 menit dan delay 0,3 menit.

\section{Penyerahan Obat}

Hasil penelitian waktu tunggu resep non racikan pada tahapan pemberian etiket adalah sebagai berikut :

\begin{tabular}{c|c|c|c|c|c|c|}
$\begin{array}{c}\text { Penyiapan } \\
\text { Obat }\end{array}$ & \multicolumn{2}{|c|}{$\begin{array}{c}\text { Pemberian } \\
\text { Etiket }\end{array}$} & \multicolumn{2}{|c|}{$\begin{array}{c}\text { Penyerahan } \\
\text { Obat }\end{array}$} & \multirow{2}{*}{ Total } \\
\cline { 1 - 5 } T & D & T & D & T & D & \\
\hline 894,9 & 22,7 & 211,5 & 22,9 & 108,2 & 14,9 & 1436 \\
\hline 12,1 & 0,3 & 2,9 & 0,3 & 1,5 & 0,2 & 19,4 \\
\hline
\end{tabular}

Hasil penelitian yang dilakukan di RSUD Dr. H. Abdul Moeloek tahapan penyerahan obat non racikan membutuhkan rata - rata waktu tindakan 1,6 menit dan delay 0,3 menit.

\section{Resep Racikan}

Dari hasil penelitian dapat dilihat waktu tunggu pelayanan resep racikan berdasarkan tahapan pelayanan resep sebagai berikut :

Tabel 4.3 Resep Racikan

Keterangan:
$\mathrm{T}=$ Tindakan
$\mathrm{D}=$ Delay

Hasil penelitian yang dilakukan di RSUD Dr. H. Abdul Moeloek diperoleh data dari 74 sampel resep racikan rata - rata waktu penerimaan resep tindakan 0,6 menit dan tidak ada delay, verifikasi resep tindakan 1,1 menit dan delay 0,5 menit, penyiapan obat tindakan 12,1 menit dan delay 0,3 menit, pemberian etiket tindakan 2,9 menit dan delay 0,3 menit, penyerahan obat tindakan 1,5 menit dan delay 0,2 menit.

\section{Penerimaan Resep}

Hasil penelitian waktu tunggu resep racikan 
pada tahapan peneriman resep adalah sebagai berikut :

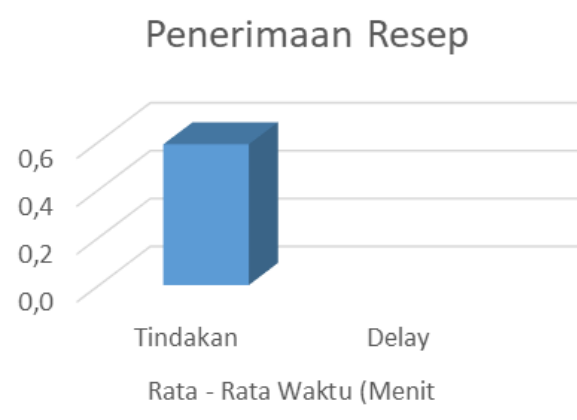

Gambar 4.6 Penerimaan Resep Racikan

Hasil penelitian yang dilakukan di RSUD Dr. H. Abdul Moeloek tahapan penerimaan resep racikan membutuhkan rata - rata waktu tindakan 0,6 menit dan tidak terdapat delay. Tahapan penerimaan resep pada resep racikan sama dengan penerimaan resep non racikan karena loket pada penerimaan resep yang sama.

\section{Verifikasi Resep}

Hasil penelitian waktu tunggu resep racikan pada tahapan verifikasi resep adalah sebagai berikut :

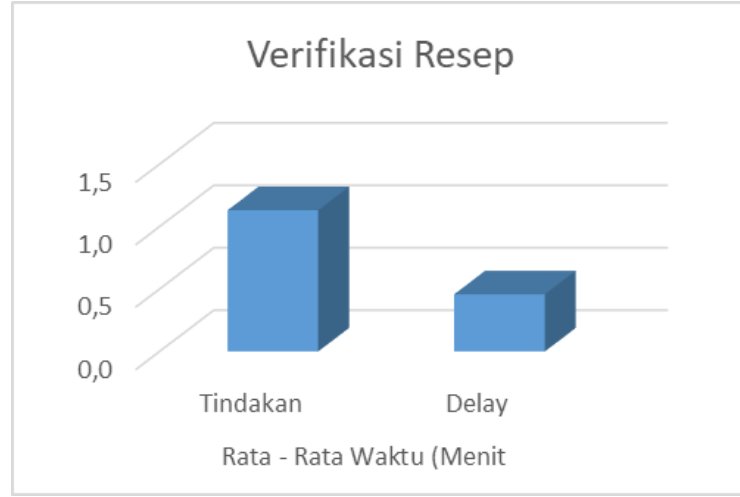

Gambar 4.7 Verifikasi Resep Racikan

Hasil penelitian yang dilakukan di RSUD Dr. H. Abdul Moeloek tahapan penerimaan resep non racikan membutuhkan rata - rata waktu tindakan 1,1 menit dan delay 0,5 menit.

\section{Penyiapan Obat}

Hasil penelitian waktu tunggu resep racikan pada tahapan penyiapan obat adalah sebagai berikut :

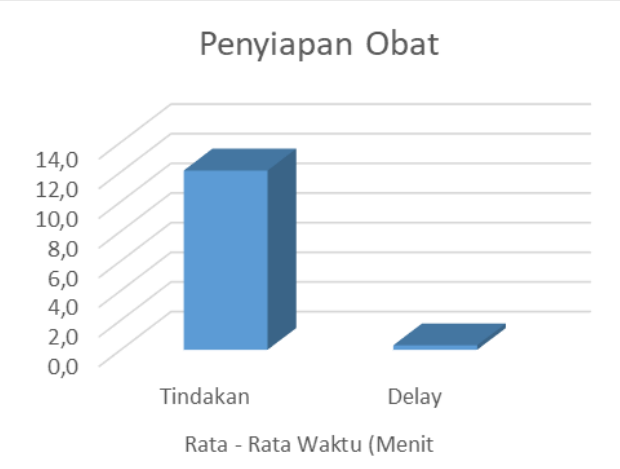

Gambar 4.8 Penyiapan Obat Racikan

Hasil penelitian yang dilakukan di RSUD Dr. H. Abdul Moeloek tahapan penyiapan obat racikan membutuhkan rata - rata waktu tindakan 12,1 menit dan delay 0,3 menit. 


\begin{tabular}{|c|c|c|c|c|c|c|c|c|c|c|c|c|}
\hline \multirow{2}{*}{\multicolumn{2}{|c|}{ Jenis Resep }} & \multicolumn{2}{|c|}{$\begin{array}{c}\text { Penerim } \\
\text { aan } \\
\text { Resep }\end{array}$} & \multicolumn{2}{|c|}{$\begin{array}{l}\text { Verifikasi } \\
\text { Resep }\end{array}$} & \multicolumn{2}{|c|}{$\begin{array}{c}\text { Penyiapa } \\
\text { n Obat }\end{array}$} & \multicolumn{2}{|c|}{$\begin{array}{c}\text { Pemberia } \\
\text { n Etiket }\end{array}$} & \multicolumn{2}{|c|}{$\begin{array}{c}\text { Penyera } \\
\text { han } \\
\text { Obat }\end{array}$} & \multirow[t]{2}{*}{ Total } \\
\hline & & $\mathbf{T}$ & D & $\mathbf{T}$ & $\mathbf{D}$ & $\mathbf{T}$ & $\mathbf{D}$ & $\mathbf{T}$ & $\mathbf{D}$ & $\mathbf{T}$ & & \\
\hline \multirow{2}{*}{$\begin{array}{c}\text { Resep } \\
\text { Non } \\
\text { Racika } \\
\text { n } \\
\end{array}$} & \multirow{2}{*}{$\begin{array}{l}\text { Jumlah } \\
\text { Rata - } \\
\text { Rata }\end{array}$} & $\begin{array}{c}57, \\
6\end{array}$ & 0 & 80,4 & $\begin{array}{c}42, \\
9\end{array}$ & $\begin{array}{c}291, \\
9\end{array}$ & $\begin{array}{c}28, \\
8\end{array}$ & $\begin{array}{c}328, \\
7\end{array}$ & $\begin{array}{c}33, \\
1\end{array}$ & $\begin{array}{l}15 \\
5,4\end{array}$ & $\begin{array}{c}24, \\
5\end{array}$ & $\begin{array}{c}1083 \\
4\end{array}$ \\
\hline & & 0,6 & 0 & 0,8 & 0,4 & 3,0 & 0,3 & 3,4 & 0,3 & 1,6 & 0,3 & 11,0 \\
\hline \multirow{2}{*}{$\begin{array}{c}\text { Resep } \\
\text { Racika } \\
\text { n }\end{array}$} & \multirow{2}{*}{$\begin{array}{l}\text { Jumlah } \\
\text { Rata- } \\
\text { rata }\end{array}$} & $\begin{array}{c}43 \\
3\end{array}$ & 0 & 83,7 & $\begin{array}{c}33 \\
9\end{array}$ & $\begin{array}{c}894, \\
9\end{array}$ & $\begin{array}{c}22, \\
7\end{array}$ & $\begin{array}{c}211 \\
5\end{array}$ & $\begin{array}{c}22, \\
9\end{array}$ & $\begin{array}{l}10 \\
8,2\end{array}$ & $\begin{array}{c}14 \\
9\end{array}$ & 1436 \\
\hline & & 0,6 & 0,0 & 1,1 & 0,5 & 12,1 & 0,3 & 2,9 & 0,3 & 1,5 & 0,2 & 19,4 \\
\hline
\end{tabular}

\section{Pemberian Etiket}

Hasil penelitian waktu tunggu resep racikan pada tahapan pemberian etiket adalah sebagai berikut :

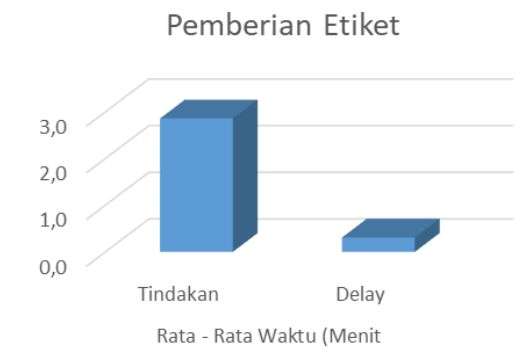

Gambar 4.9 Pemberian Etiket Racikan

Hasil penelitian yang dilakukan di RSUD Dr. H. Abdul Moeloek tahapan pemberian etiket racikan membutuhkan rata - rata waktu tindakan 2,9 menit dan delay 0,3 menit.

\section{Penyerahan Obat}

Hasil penelitian waktu tunggu resep racikan pada tahapan penyerahan obat adalah sebagai berikut :

Penyerahan Obat

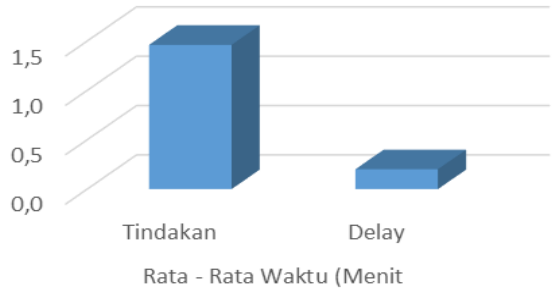

Gambar 10 Penyerahan Obat Racikan
Tabel 4.4 Resep Non Racikan dan Racikan Keterangan:

$\mathrm{T}=$ Tindakan

$\mathrm{D}=$ Delay

Hasil penelitian yang dilakukan di RSUD Dr. H. Abdul Moeloek tahapan penyerahan obat non racikan membutuhkan rata - rata waktu tindakan 1,5 menit dan delay 0,2 menit.

\section{SIMPULAN DAN SARAN}

\section{A. Simpulan}

1. Waktu tunggu pelayanan resep non racikan di Instalasi Rawat Jalan RSUD Dr. $\mathrm{H}$. Abdul Moeloek sudah sesuai dengan SPM di Rumah Sakit dengan waktu tunggu rata - rata 11 menit.

2. Waktu tunggu pelayanan resep racikan di Instalasi Rawat Jalan RSUD Dr. H. Abdul Moeloek sudah sesuai dengan SPM di Rumah Sakit dengan waktu tunggu rata rata 19,4 menit.

3. Perbedaan waktu tunggu resep non racikan dan racikan terdapat pada tahapan verifikasi dan penyiapan obat.

\section{B. Saran}

1. Penelitian dengan tema sejenis disarankan untuk mencoba meneliti lama waktu tunggu berdasarkan 


\section{JFL}

perbedaan jumlah item obat yang diresepkan.

\section{DAFTAR PUSTAKA}

1. Setya Enti Rukinah. Farmasi Rumah Sakit. Yogyakarta: Deepublish Publisher; 2017.

2. Menteri Kesehatan Republik Indonesia. PERMENKES RI No. 56 Tahun 2014 Tentang Klasifikasi Dan Perizinan Rumah Sakit. 2014;

3. Menteri Kesehatan Republik Indonesia. PERMENKES No. 72 Tahun 2016 Tentang Standar Pelayanan Kefarmasian Di Rumah Sakit. 2016;

4. Menteri Kesehatan Republik Indonesia. KEPMENKES No. 129/Menkes/SK/II/2008 Tentang Standar Pelayanan Minimal Rumah Sakit. 2008;

5. Nurma Katrinnada Purwandari. Analisis Waktu Tunggu Pelayanan Resep Pasien Rawat Jalan Di Depo Farmasi Gedung MCEB RS Islam Sultan Agung Semarang. J Kesehat Masy. 2017;5.
2. Sebaiknya pelayanan Resep BPJS dan Resep Umum disediakan pada tempat yang terpisah.

6. Nur Laeliyah. Waktu Tunggu Pelayanan Rawat Jalan dengan Kepuasan Pasien Terhadap Pelayanan di Rawat Jalan RSUD Kabupaten Indramayu. J Kesehat Vokasional. 2017;1.

7. Septini R. Analisis Waktu Tunggu Pelayanan Resep Pasien Askes Rawat Jalan di Yanmasum Farmasi RSPAD Gatot Subroto tahun 2011. Depok: Fakultas Kesehatan Masyarakat Univesitas Indonesia; 2012

8. Febri Enda Budi Setiawan. Menejemen Rumah Sakit. Sidoarjo: Jafatama Jawara; 2019.

9. Siregar. Farmasi Rumah Sakit: Teori dan Penerapan. Jakarta: Buku Kedokteran EGC; 2004.

10. Widiasari E. Analisa Waktu Pelayanan Resep di Instalasi Farmasi Rawat Jalan RS Tugu lbu Depok Tahun 2009. Skripsi Universitas Indonesia. Depok; 2009. 